Revista de la red interuniversitaria de estudios sobre las literaturas rioplatenses contemporáneas en Francia

$23 \mid 2021$

La vereda de enfrente. Cruces entre las literaturas argentina y chilena del siglo XX

\title{
Las tradiciones reescritas de Claudia Apablaza
}

Les traditions rééecrits de Claudia Apablaza

The rewritten traditions of Claudia Apablaza

\section{Andrés Olaizola}

\section{OpenEdition}

\section{Journals}

Edición electrónica

URL: https://journals.openedition.org/lirico/11677

DOI: 10.4000/lirico.11677

ISSN: 2262-8339

Editor

Réseau interuniversitaire d'étude des littératures contemporaines du Río de la Plata

Referencia electrónica

Andrés Olaizola, «Las tradiciones reescritas de Claudia Apablaza», Cuadernos LIRICO [En línea], 23 |

2021, Publicado el 09 diciembre 2021, consultado el 07 enero 2022. URL: http://

journals.openedition.org/lirico/11677 ; DOI: https://doi.org/10.4000/lirico.11677

Este documento fue generado automáticamente el 7 enero 2022.

\section{c) (i) $९$}

Cuadernos LIRICO está distribuido bajo una Licencia Creative Commons Atribución-NoComercialSinDerivar 4.0 Internacional. 


\title{
Las tradiciones reescritas de Claudia Apablaza
}

\author{
Les traditions rééecrits de Claudia Apablaza \\ The rewritten traditions of Claudia Apablaza
}

Andrés Olaizola

\section{Introducción}

1 En este artículo examinaremos las modalidades con las que las literaturas argentina y chilena del siglo XX se recrean en un corpus de textos de Claudia Apablaza. Por un lado, en los textos específicamente literarios, Apablaza, a través de distintos procedimientos (el de la cita, entre otros) y figuras (por ejemplo, la de la biblioteca), vuelve sobre zonas de las tradiciones literarias argentina y chilena, y propone una lectura de cierta representación del/ de la escritor/a latinoamericano/a en la actualidad. Por otro lado, en textos ensayísticos y periodísticos (ponencias, reseñas, prólogos) sobre escritoras contemporáneas argentinas y chilenas, Apablaza destaca como rasgos comunes en los textos de las autoras que analiza ciertas características formales y temáticas, las cuales son similares a los que nosotros hemos identificado en la producción literaria de la misma Apablaza.

2 Habría entonces en los cuentos y novelas de Apablaza una lectura de los cánones literarios modernos de Argentina y de Chile, así como reflexiones sobre una determinada figura del/ de la escritor/a latinoamericano/a correspondiente a los últimos veinte años. Las referencias a Borges, Piglia, Cortázar, entre otros, son variadas; lo mismo pasa con Bolaño, Rojas, Nicanor Parra, pero todas se dan en el marco de textos que se alejan de esos modelos literarios (sobre todo en lo que se refiere a su poética, a su narrativa), para desde esa diferencia, plantear su propuesta estética: la de la "no historia", la de la secuencia de anécdotas nimias, la del fragmento documental. Acaso esto constituya una respuesta o una declaración que viene a afirmar que hoy en día ya no es posible (y/o tampoco deseable) escribir textos como estos hombres (y la referencia al género no es casual), porque, en tiempos en que los sistemas literarios están traccionados por las 
becas y premios literarios, los grandes conglomerados de comunicación y edición, y los medios digitales interconectados, se ha conformado un imaginario alternativo del escritor/a de América Latina.

3 Los prólogos, reseñas y textos académicos de Apablaza nos ofrecen una lectura de escritoras a ambos lados de la cordillera de los Andes, en donde podemos establecer, además de una cercanía generacional, vínculos en lo que respecta a su poética y a la práctica escritural en tanto autoras latinoamericanas contemporáneas. Podríamos postular que el diálogo, en vez de establecerse de manera explícita, se daría a partir de la propia producción literaria de Apablaza: lo que ella destaca a nivel formal tanto de las escritoras chilenas como de las argentinas, también lo localizamos en sus textos narrativos.

El presente artículo analizará textos literarios y críticos de Claudia Apablaza. Se examinarán sus libros de cuentos Autoformato (2006), Siempre te creíste la Virginia Woolf (2011) y Todos piensan que soy un faquir (2013). A su vez, también se trabajará con las novelas Diario de las especies (2008), EME/A: la tristeza de la no historia (2010), GOØ y el amor (2012) y Diario de quedar embarazada (2017). Por otro lado, nuestro corpus está conformado con la reseña "Anti-cuentos, fracaso narrativo, belleza y felicidad" (2010), el prólogo "Infancia y desarraigo" (2011), y la entrevista que Gianna Schmitter le realizó a Apablaza (2016).

\section{El experimento y el juego como formas de narrar}

5 Claudia Apablaza nació en Rancagua en 1978. Estudió psicología y realizó una maestría en estudios literarios en la Universidad de Chile. En 2005 ganó el premio de la revista Paula por su cuento "Mi nombre en el Google". Un año más tarde, ese texto se incluyó en su primer libro de relatos: Autoformato. Luego de las novelas Diario de las especies y EME/A: la tristeza de la no historia, y del libro de cuentos Siempre te creíste la Virginia Woolf, gana en el 2012 el Premio Latinoamericano de Novela Alba Narrativa con GOØ y el amor. Tras Todos piensan que soy un faquir, su último libro publicado es la novela Diario de quedar embarazada. Además de las novelas y los cuentos, Apablaza escribe artículos sobre literatura contemporánea, entrevistas a escritores/as y reseñas. Una de ellas es “Anti-cuentos, fracaso narrativo, belleza y felicidad”, reseña de Volveré y seré la misma. Panorama de nuevas narradoras argentinas, antología que edita Francisco Garamona con textos de Dalia Rosetti, Gabriela Bejerman, Fernanda Laguna, Susana Pampín, Cecilia Pavón e Inés Acevedo. Para Apablaza, los textos de la antología son "anti-cuentos, en los que las autoras de estas historias huyen de discursos hegemónicos y se encierran en una intimidad que va levantando capas y capas, donde no hay un miedo a contar, a fracasar en el texto" (Apablaza 2010c).

6 En Apablaza, la posibilidad de narrar se presenta como una imposibilidad. Diario de las especies abre con esta declaración de la narradora A.A.: "Apenas llegué a Barcelona olvidé qué es escribir una novela, entre otras cosas" (Apablaza 2010: 7). Y como perdió la noción del procedimiento de la escritura ficcional, decidió hacer un blog "en relación a la búsqueda de las formas de escribir una novela" (Apablaza 2010: 7). Las formas de la narración perdidas tratan de buscarse en otras escrituras, en este caso digitales, que son presentadas por la narradora como algo ajeno al relato, pero que en realidad no lo son. Porque lo que Diario de las especies demuestra es que las entradas de un blog, que aparentemente no son una novela, al final sí la terminan constituyendo. 
7 En Diario de quedar embarazada, la narradora lee el diario que ella había llevado cuando estuvo en una residencia de escritores/as, con el objetivo de escribir una novela. Pero a la narradora no le interesaba la narración, en realidad su único deseo era embarazarse:

Dicen que una tiene que elegir cuándo y dónde y de quién quiere quedar embarazada. Lo he elegido, es este lugar. Me quedan 40 días acá y nadie debe notar que vine a eso. Debo simular que escribo, que trazo estructuras literarias, índices, finales, que diseño personajes, voces, capítulos (Apablaza 2017: 24).

8 Y eso es lo que ocurre: durante toda su estadía no escribe la novela. Pero lo que terminamos leyendo se constituye como tal.

9 El procedimiento se vuelve casi un chiste: la voz narradora declara no poder y/o no querer narrar, por lo tanto, escribirá textos a los que considera "no narrativos", como un diario en Word o un blog, textos en donde lo digital es constitutivo de su forma, pero no definitorio, ya que remedan medios y géneros anteriores (Bolter \& Grusin 2000). Los textos se sucederán, las narradoras declararán insistentemente que se alejan de la narración, pero cuando se despliega la última entrada de la bitácora, el último texto, efectivamente leemos que se ha conformado una narrativa. Similar situación ocurre en GOØ y el amor: los escritos de GOØ (tuits, publicaciones de blog, entradas de diario) conformarán el texto narrativo de una narradora que nunca explicita el deseo de escribir una novela o un cuento. Asimismo, Apablaza destaca que las autoras de Volveré y seré la misma

no cierran un círculo, sino que establecen líneas de fuga hacia ninguna parte a veces, toman voces que van mutando y cambiando, provocando todas un cuestionamiento de lo que es la estructura del cuento, que lo conflictúan en su fondo y forma, lanzándose con una cierta bella torpeza a contar, con belleza y felicidad (Apablaza 2010c).

"Líneas de fuga" lejos de cierto canon narrativo, de determinada manera narrar que, paradójicamente, impide construir el relato. La narradora de "Poseída", incluido en Siempre te creíste la Virginia Woolf, dice que está poseída por un "ente vivo" que "goza de una vigencia eterna" (13): está poseída por el corpus "ideal y además ficticio" (11) de la narración. Ese cuerpo textual "penetra con desenfreno" (11), la toma, se apropia de ella, y sin embargo impide toda narración: "Estoy poseída por la diégesis. Mi nombre es Claudia. Tengo algunos momentos de lucidez en que la diégesis me abandona y puedo decir esto que relato" (9). El corpus narrativo ideal, el que posee a "algunos hombres ligados a las letras" (9), aprisiona a la narradora, la ata, la amarra (11). Un corpus/ cuerpo de algunos hombres subyuga a la narradora y no le permite construir un relato.

Gonzalo León sostiene de Siempre te creíste la Virginia Woolf:

El narrador de muchos de estos relatos se burla de todas las clases de escritores, de los agentes, de las ferias del libro, de los profesores de literatura. El misterio de la creación, parece indicar este narrador descreído o ateo, no se encuentra en el medio literario que es pretexto, sino en los textos y sus mecanismos. Ambos indisolublemente unidos. Son los textos de Apablaza y sus mecanismos los que hablan de todos los textos y de todos los mecanismos que están contenidos en la diégesis (2011).

12 El medio literario, podríamos decir, es la excusa para desarrollar textos en donde nos alejamos del "corpus narrativo ideal", para plantear narrativas que "fracasan", que van "hacia ninguna parte". En Siempre te creíste la Virginia Woolf podemos ver varios ejemplos: en "Soy", la narradora solo espera en una fila para ver a un "gran crítico literario latinoamericano dar la tremenda conferencia magistral" (21); en "Parece que 
mi agente literario me odia", la narradora trata de comunicarse con su agente literario; y en "Yo me paseo", la narradora le cuenta a un médico cómo se paseaba por la Feria Internacional del Libro. Esperas, paseos, charlas nimias: lo narrativo parece reducirse a situaciones como éstas, acaso "anti" narrativas. Más allá de diseñar "estructuras literarias, índices, finales, [...] personajes, voces, capítulos” (Apablaza 2017: 24), en Apablaza, escribir "es también no saber dónde se caerá" (Apablaza 2011a: 7). Porque tal vez, diferenciándose de cierto canon, los textos narrativos de Apablaza, "dejan de ser historias" y narran una conceptualización de la literatura, de la escritura, "donde lo narrativo es lo menos importante" (León 2011). En lugar de una gran historia sin fallas, que siga las reglas de un canon, se construyen narraciones más reducidas, que sin embargo siguen narrando, a partir de fragmentos y referencias literarias varias.

Yo perfectamente me podría creer Fogwill, como todos los narradores; o Phillip Roth, Thomas Bernhard, Caballito Seguel, Fernando Pessoa, Bukowski, Robert Walser, Jirafita Buenaventura, José Donoso, Roberto Bolaño, Chanchito Olmos. Y caminar, pensar, imitarlos, bailar como ellos. Pero no necesito caer en eso, no necesito estar jugando a eso, [...] menos repetir en cada entrevista la detestable teoría del iceberg ni la del knock out; ni tampoco pedirle a una transnacional que me publique, que me llame por teléfono todos los días para no sentirme tan solo, y luego viajar por el mundo en muchos aviones, en un pedazo de papel, y luego volver a Chile y decir que soy mejor que Fogwill, [...] y seré muy famoso, que merezco respeto, seguridad, salir en las revista nacionales, internacionales como la nueva figura de la literatura latinoamericana, como el representante número uno de la nueva fauna (Apablaza 2011a: 32).

El narrador de "Siempre te creíste la Virginia Woolf", un "aspirante a escritor misógino que se creía Fogwill un día y Carver al día siguiente" (33), hace una lista solo de narradores, menciona algunas "teorías" elaboradas por escritores para explicar su proceso compositivo y establece como condición sine qua non comportarse de cierta manera para convertirse en "la nueva figura de la literatura latinoamericana".

Las narraciones se presentan muchas veces por las mismas voces narradoras como ajenas a la historia, al relato, y emplean formas fragmentarias y breves (publicación de blog, tuit, entrada de diario) que se entienden casi como "anti narrativas", pero que al final del texto sí evidencian la construcción de una historia. Al mismo tiempo, también se desarrollan formas como el paseo, la espera, en donde la voz narradora suele charlar o monologar y la historia parece no avanzar e incluso detenerse. Este alejamiento de ciertas estructuras del relato derivadas de cierto "canon narrativo" se hace evidente cuando los/as narradores/as de los cuentos y las novelas de Apablaza aluden a escritores de las tradiciones literarias argentina y chilena modernas (incluso podríamos decir occidental). Al citar a Cortázar, Fogwill, Donoso, Bolaño, entre otros, se evidencian algunos procedimientos narrativos que desarrollaron estos escritores y otros de la "tradición moderna", pero sobre todo se destaca el carácter masculino de cómo se ha construido esa tradición, la de Chile, la de Argentina y la del canon occidental: se los reconoce como antecedentes literarios para valorar, pero al mismo los textos narrativos se organizan alejados de esos modelos de escritores hombres donde la estructura del relato es central. No es casual tampoco que la escritora más gravitante en la trama de dos textos de Apablaza sea una poeta, Sylvia Plath ("Creo que te inventé en mi mente", de Siempre te creíste la Virginia Woolf; y GOØ y el amor).

Las instituciones literarias y culturales, los conglomerados de medios, prensa y edición legitiman ese canon narrativo (de hombres) y construyen una determinada figura de escritor/a latinoamericano/a que la mayoría de los/as personajes que escriben en los 
textos de Apablaza toman como modelo: En "El mejor" se narra una fiesta en Nueva York a la cual asisten escritores latinoamericanos que tratan de saber cuál de ellos es efectivamente "el mejor" autor, ya que cada uno de ellos había sido catalogado "por la crítica especializada como el mejor escritor latinoamericano contemporáneo". Todos los escritores

repetían cada treinta minutos o cuando se les daba la ocasión: ¿Sabías que en El País me nombraron como el mejor escritor latinoamericano? Oh, a mí también. El mejor escritor latinoamericano vivo. A mí también. Menos mal, ya no limpiaré cañerías ni wáteres. Ay, yo también. ¿Sabías que en El Mundo y en La Vanguardia me apuntaron como el mejor escritor latinoamericano vivo? ¿Y en el New York Times? (Apablaza 2011a: 26).

16 Además de postular una determinada idea del texto narrativo, de las tradiciones literarias argentina y chilenas, de la figura de "escritor latinoamericano" en la actualidad, el corpus que analizamos desarrolla una idea sobre la literatura. Casi como una definición de su propia poética, Apablaza considera que "para las escritoras que firman Volveré y seré la misma la mejor literatura es la que funciona a modo de ensayo" (Apablaza 2010c). Para las escritoras antologadas, y agregaríamos para Apablaza, la mejor literatura es "una especie de experimento libre y desbocado", que "le ha perdido el miedo momentáneo a esas grandes teorías y padres literarios y se los mete al bolsillo o que juega con ellos en la soledad de la escritura" (Apablaza 2010c).

La literatura en Apablaza puede entenderse como juego, como experimento de relectura y reescritura de las tradiciones literarias, de las formas que esos "grandes hombres" han empleado para conformar el relato. Esa literatura como ensayo no teme parecer "anti narrativa" ni jugar con los cánones: "He ahí el concepto de ensayo, y he ahí la estética del posible fracaso, de lanzarse a ciegas cada una a su proyecto literario, matando madres, vacas sagradas, desmitificando narrativas que tienen su momento histórico y su contexto de origen" (Apablaza 2010c).

Apablaza sostiene que la literatura es "un gesto de voluntad" (Schmitter 2016: 13). ¿Hacia quién? Hacia el/la lector/a y hacia el/la escritor/a, afirma, pero es también un gesto de voluntad hacia ese experimento, juego, ensayo textual que desarrolla conexiones casuales y efímeras entre los personajes, pero que son las que traccionan el relato, muchas veces empleando formas fragmentarias, dispersas y breves, vinculadas a menudo con las escrituras del yo. Para Apablaza, la narración, lejos de basarse en estructuras sólidas, sin fallas, simplemente "tiene que ver con contar una historia, con contar algo que tenga un mínimo de temporalidad. [...] Cuando está presente el tiempo, el cambio interno, ya hay narración" (Schmitter, 2016, 15).

19 Es interesante la relación que Apablaza entabla en la reseña entre juego, ensayo y experimento, y es posible extenderla hacia sus textos narrativos. El juego con citas y referencias a las tradiciones literarias, con textos y estéticas (digitales), con casualidades y vínculos azarosos, ensaya una determinada concepción de la literatura, la cual se aleja de ciertos cánones narrativos, pero que sigue componiendo relatos.

Acá hay autoficción, hay dispersión narrativa, hay giros inimaginables, hay imaginarios abiertos a que los siga sin temor la pluma de cada una de estas seis escritoras, hay incluso torpeza, falta de tensión narrativa, anécdotas de calle, cuentos que podrían ser para niños o susurrados al oído. Acá no hay vigilancia, acá no hay poder total sobre el texto, acá no hay miedo a la dispersión, acá no hay nadie que quiera guardar en su mesita de noche la etiqueta de la mejor narradora argentina (Apablaza 2010c). 

podemos leerlo en el corpus de la escritora chilena.

\section{Bibliotecas y libros imposibles}

La reescritura de las tradiciones literarias argentina y chilena del siglo XX no solamente se daría a través de un distanciamiento de cierto canon narrativo masculino (que sin embargo implica su reconocimiento como antecedente), a partir del desarrollo de ciertas estructuras narrativas dispersas y fragmentarias, en donde la concepción del juego y el experimento está presente. La recreación de las tradiciones se realiza también a partir de la aparición repetida de algunas figuras en los textos de Apablaza. La biblioteca es una de estas figuras.

La biblioteca, materialización de un entramado de textos y nombres donde además se cruzan espectros y cuerpos, es vital, por ejemplo, para la bloguera A.A. de Diario de las especies: "La gran biblioteca me palpa, me excita, me traga" (Apablaza 2010a: 46).

La figura de la Biblioteca como pulsión, pero también como, en definitiva, domicilio último que desean habitar los personajes y los/as narradores/as (para a su vez ser habitados/as por Ella) es una constante en los textos de Apablaza: desde los/as escritores/as de los cuentos de Siempre te creíste la Virginia Woolf, que ansían ser aprehendidos, poseídos por la biblioteca de la "literatura latinoamericana"; pasando por la protagonista de GOØ y el amor, que es guiada en viajes a Benidorm y a Portbou por los espectros textuales de Benjamin y Plath que claman desde sus mausoleos. Llegar a, estar en, ser incluido en la biblioteca son acciones que jalonan la consignación hacia un orden literario, ya sea canónico, anticanónico o alternativo. Sin embargo, es una biblioteca imposible, o mejor dicho, son distintas representaciones de una misma imposibilidad.

La biblioteca de Barcelona, ciudad que es en sí misma "una gran biblioteca" (Apablaza 2010a: 11), en Diario de las especies, es un espacio en el cual, antes del cierre, se esconden las/os usuarios/as para dormir y tener sexo entre ellos/as (35). El hecho de habitar, de domiciliarse allí, transforma el deseo: "Estar dentro de esta gran biblioteca cambia las pasiones" (71).

En EME/A La tristeza de la no historia, se narra la conformación de una biblioteca de manuscritos inéditos que es la piedra basal de la "no historia de la literatura universal". El gesto de la catalogación de una literatura que no debe salir a la luz, cuyos manuscritos se queman apenas se editan, es el punto de partida para leer el desplazamiento de la narradora en y a través de Chile, en los entornos digitales interconectados, y también, en la tradición literaria chilena. Los manuscritos de esta biblioteca imposible no solo se queman, también se roban: "Los robos sobre robos nos tienen confundidos" (Apablaza 2010b: 20). Aún con la expurgación, con la sustracción, la biblioteca no para de crecer: "A los seis meses tuve que cambiarme de casa. Al año alquilé una antigua biblioteca del barrio para seguir" (16).

No solo encontramos que la colección es imposible, sino que el objeto coleccionado también lo es: los libros de las bibliotecas distan de ser simplemente apócrifos, directamente son ilegibles por su extensión, incapaces de ser escritos por su masividad. Tan ridículas como imposibles son la "No historia de la literatura universal", de EME/A La tristeza de la no historia; la "Historia de la Web", que un usuario desea realizar 
documentando toda la información que se produce segundo a segundo en Internet (14-15); o la novela acerca de la "frecuencia de los sintetizadores" (31), ejemplos pertenecientes a Diario de las especies.

De especial relevancia es el libro apócrifo Un mito para cada uno de los chilenos, en donde Roberto Bolaño "le dejó a cada uno de los chilenos un pequeño mito". Leemos:

¿Conoces el libro Un mito para cada uno de los chilenos? [...] Guardado en los Archivos de la Biblioteca Nacional. A uno le piden el carnet de identidad y le dicen: Búsquese en ese libro. [...] Bolaño fue generoso con el pueblo chileno. Hizo un listado del uno a los veinte millones (Apablaza 2010a: 66).

Además de inabarcable, es premonitorio, ya que, en ese momento, la población de Chile era de dieciséis millones de personas y "Bolaño previó que en algún momento llegaría a veinte millones o más" (67). Un mito para cada uno de los chilenos es de imposible factura y xenófobo al mismo tiempo:

Sabrás que la población de Chile asciende a dieciséis millones. Bolaño previó que en algún momento llegaría a veinte millones o más. A los peruanos les dan números desde los veinte millones hacia arriba. Es decir, ellos no pueden ir con su carnet de identidad a buscarse en esas listas. Bolaño le dejó esa herencia sólo al pueblo chileno. Sólo dieciséis millones de mitos (Apablaza 2010a: 67).

Michel Foucault esboza dos figuras ejemplares, contrapuestas, pero a la vez complementarias entre sí, de lo que es la literatura. Por un lado, está la figura de la transgresión, del habla transgresora, del lenguaje en el límite. Por otro lado, está la figura de la biblioteca, del espacio de los libros que se acumulan, de las palabras que apuntan hacia la literatura. Para Foucault, las figuras de lo prohibido y de la biblioteca, configuran, en "el sistema mismo de su pertenencia mutua", la experiencia moderna de la literatura; el habla de la transgresión y la eternidad absoluta de los libros catalogados y guardados distribuyen "lo que podría llamarse el espacio propio de la literatura" (1996: 69-71).

30 Es posible apelar a estos dos polos para ofrecer una reflexión sobre los textos de Apablaza que estamos analizando: por un lado, la experimentación del juego con las formas narrativas; por el otro, la tradición, el archivo de materiales culturales y literarios, los espectros del pasado lejano o cercano que aparecen de diferentes maneras en la superficie y en los intersticios del texto. Hay un deseo de ir hacia la biblioteca, de pertenecer y domiciliarse en ella, lo que es otra forma de querer ser parte de una tradición: "He decidido cerrar este post por unos días. La gran biblioteca me exige absoluta oscuridad y silencio. Me ha tragado" (Apablaza 2010a: 131).

31 Más allá de las estéticas de las tecnologías que caracterizan a muchos de los textos de Apablaza, lo cierto es que, por un lado, los géneros y las estrategias digitales que se trabajan en las novelas de la escritora chilena remedan géneros de la modernidad: en Diario de las especies, GOØ y el amor y Diario de quedar embarazada, las formas narrativas de la novela epistolar y del diario personal son claramente visibles. Los protocolos del chat, del tuit, del correo electrónico, etc., presentes en los textos pueden entenderse como una "dimensión residual de lo epistolar que ha ejercido una gran presión sobre la composición literaria" (Chejfec 2015: 69). Narrativas como la de Apablaza estarían construidas con "criterios de reproducción escenográfica de las pantallas" basados en extrapolar las estéticas digitales a formatos literarios convencionales (Chejfec 2015: 70). Ya desde cuentos como "Mi nombre en el Google", "Dos poetas desconocidos ejecutan una acción importante", o "Respuestas para una entrevista de una revista top", de 
Autoformato, se cifra el deseo de ser publicado en el extranjero, de aparecer en revistas "caras" y en suplementos culturales, de recibir reseñas positivas en El País, de ganar becas: de ser un/a escritor/a del canon literario (impreso).

Soledad Bianchi plantea que en la posdictadura chilena, la cultura se concibe como un espectáculo, como un adorno, y el escritor es una figura mediática y comercial (2014). El hecho de formar parte de la biblioteca es alcanzar visibilidad pública, validez académica y editorial. Tal como declara Apablaza en una entrevista, "los escritores chilenos de ahora, como que siento que escriben para figurar" (Schmitter 2016: 13). La conformación de una biblioteca (física, virtual, real, imaginaria, apócrifa, de libros, de fragmentos, de textos editados, de textos inéditos) evidencia una perspectiva de lectura, una forma de leer los sistemas literarios. Las figuras de la biblioteca y del libro imposibles son otras de las formas que Apablaza emplea para recrear las tradiciones de Chile y de Argentina. En los textos del corpus se observa un deseo de formar parte de la biblioteca, pero ello no se cumple. La principal razón es el aspecto que, sobre todo, se va a subrayar de estas tradiciones literarias. La imposibilidad constitutiva de la biblioteca radica en el hecho de no se puede formar parte de ella, dado que solo la integran escritores hombres, ya sean chilenos, argentinos, europeos o estadounidenses.

En "Las diez víctimas de Nasón", el personaje de Nasón le da a su secretario Carlos una lista de diez mujeres que debe traer ante él:

Marguerite Duras, Sylvia Plath, Virginia Woolf, Simone de Beauvoir, Gabriela Mistral, María Luisa Bombal, Silvina Ocampo, Victoria Ocampo, Esther Tusquets, Diamela Eltit, Ana María Moix, Emily Brönte, Alejandra Pizarnik, Juana de Ibarbourou.

Nasón quiere vengarse de ellas, porque pudieron publicar y su difunta esposa no. Carlos, luego de investigar en Internet, le dice a su jefe:

-[...] La mayoría de ellas están muertas. No las voy a poder traer.

-Carlos, encuentra en esta ciudad a cada una de sus iguales (Apablaza 2006: 8-9).

No importa a quien pertenecen esos nombres, si están vivas o muertas, si son conocidas por mucha gente o no, o si son chilenas, argentinas, francesas o inglesas. Lo que importa para Nasón, y para una parte importante de las instituciones, individuos y dispositivos que forman parte de los procesos de conformación del canon, es que sean mujeres, esas o sus dobles. Solo diez, siempre diez, y para agregar nombres, es necesario sacar a algunos de los anteriores. Ser parte de la biblioteca, del libro, es imposible, porque corresponde a los escritores hombres, y para las mujeres solo hay contados lugares.

\section{Tradiciones masculinas}

Para Apablaza, las escritoras de Volveré y seré la misma "no quieren escuchar más ese decálogo, esa llamada de atención de los tremendos, de los grandes escritores universales". Esas autoras son "el opuesto a la vigilancia prolija de una cierta tradición literaria. Es la caída intencional de esa tradición argentina, la burla consciente y el descrédito de Borges, de Cortázar, Bioy Casares, Wilcock, Saer" (Apablaza 2010c).

En Apablaza, no creemos que sea posible hablar de descrédito, pero sí de juego con las tradiciones chilenas y argentinas, sí de distanciamiento con respecto a ciertas formas canónicas del relato que conllevan y, sobre todo, sí de un señalamiento de su carácter 
eminentemente masculino. La representación de una tradición literaria masculina en Apablaza es tan marcada que incluso va más allá de los sesgos nacionales:

Parto este blog reconociendo que soy mujer. Debo decirlo. No siempre la letra A implica que detrás de ella haya una mujer. Y entre la lista de mis escritores favoritos, no hay mujeres. Leo a Kafka, Bernhard, Bolaño, Borges, Cortázar, VilaMatas, Bukowski, Dostoievski, Roth, Tabucci, Gombrowicz, Fresán, Bioy Casares, Tomeo, Parra (Nicanor), Piglia, Arlt, Marsé, Walser, Miller, Freud, Wilcock, Juan José Saer, Onetti, Ryu Murakami, Bret Easton Ellis, Oé, Ellroy, entre cientos de otros. Un universo repleto de hombres (Apablaza 2010a: 8).

En Diario de las especies, la tradición argentina se organiza alrededor de Borges y Piglia, y en menor medida Saer, Gombrowicz y Cortázar. La figura de la biblioteca imposible con libros ídem exhibe claramente su anclaje borgeano. Es interesante observar que, cuando el procedimiento de la citación (de nuevo, Borges) es vinculado con el plagio, se destaca el papel de Piglia:

No quisiera caer en la cita de la cita de la cita de la cita de la gran cita. Ya Borges lo hizo y no encuentro razón alguna de querer plagiar a Borges. Piglia también lo hace.

Plagio Piglia. Piglia Plagio. Las letras se pueden intercambiar. Un retorcido y forzado anagrama. Si tomamos Piglia y queremos transformarla en Plagio, nos sobra de Piglia una letra i, y nos falta una: o. Si tomamos Plagio y queremos transformarlo en Piglia, nos sobra de Plagio, la letra o y nos falta una: i. (Apablaza 2010a: 95).

41 La figura de Piglia es tan gravitante como la de Borges en Apablaza: "Leía a Piglia y lo amaba y lo odiaba a la vez. Es un monstruo, un gran monstruo; o sea, es un gran y perfecto cobarde. Todo gran escritor (o gran hombre) es un perfecto cobarde a la vez. ¿De qué va su cobardía? No lo sé y no es lo que importa en este momento" (Apablaza 2010a: 8). No importa si hay o no una respuesta, lo que es verdaderamente interesante de la pregunta sobre la "cobardía" o la acusación de "plagio" es que, más allá del autor elegido, evidencia que en la conformación de una tradición literaria nacional (como la argentina en este caso, pero puede extenderse a cualquier otra) lo inmoral, lo delictual, lo falso, se convierten en variables centrales del proceso. De hecho, es el propio Piglia quien sostiene que Borges cierra las dos líneas básicas del sistema de la literatura argentina del siglo XIX: la gauchesca y el europeísmo. Para Piglia, Borges "exaspera y lleva a la parodia y al apócrifo" la tradición nacional del europeísmo, de la genealogía extranjera de la cultura argentina, es decir, toda "la historia del sistema de citas, referencias culturales, alusiones, plagios, traducciones, pastiches que recorre la literatura argentina desde Sarmiento hasta Lugones" (2000: 71-72).

"Todo gran escritor (o gran hombre) es un perfecto cobarde a la vez", leemos y podemos remitirnos una vez más a cómo se ha conformado ese canon narrativo masculino. Resuena la cobardía de imposibilitar el ingreso a las bibliotecas de las literaturas nacionales a las escritoras mujeres, o de establecer un determinado cupo implícito.

43 En este marco, podríamos referir las hipótesis de Gustavo Guerrero como una vía para seguir pensando las particularidades de la literatura de Apablaza. Ante el presentismo que se instaura a partir de la década del noventa, Guerrero identifica en varios escritores/as latinoamericanos/as una nueva estrategia de interacción temporal, que emplea la reescritura, la traducción y la citación como sus herramientas. En los textos se reacomoda, se arma, se escucha "una biblioteca de voces", cuyo objetivo no es perseguir "la reconstrucción de una continuidad, una historia o un relato único de 
filiaciones definidas", sino "poner de manifiesto creativamente la necesidad de buscar otras alternativas ante la disociación temporal que signa lo contemporáneo" (Guerrero 2018: 61-63). En los textos de Apablaza es posible observar esta estética: vamos hacia la biblioteca (argentina y chilena, en particular; occidental, en general), pero se la reescribe, se la imagina, se la imposibilita, se la transgrede, y al hacerlo se evidencian ciertos procedimientos de todo proceso de conformación de una tradición literaria.

Leemos en Todos piensan que soy un faquir: "Este texto no es más que el pensamiento de otros textos" (Apablaza 2013: 72). La estética citacionista encuentra en Borges un antecedente central, pero también en el neobarroco y en el concretismo brasileño; a lo que habría que sumar los Cantos, de Ezra Pound, La tierra baldía, de T. S. Eliot, y el Libro de los pasajes, de Walter Benjamin (Guerrero 2018; Rivera Garza 2013). A su vez, en pleno siglo XXI, la estética citacional es potenciada por las escrituras digitales y los entornos interconectados, lo cual lleva a erigirla como una práctica esencial en la poesía y la narración del siglo XXI (Perloff 2010; Goldsmith 2015).

"A mí me encanta encontrar la literatura en las conexiones" (Schmitter 2016), sostiene Apablaza, lo cual, desde luego, hace referencia a la "literaturidad" que posee Internet, pero también al procedimiento de vincular textos como modo de composición del hecho literario. Las conexiones se encuentran, se leen, se citan, y al hacerlo, se reescribe el origen de dichos textos: las tradiciones literarias argentina y chilena.

En fin, hay diversos tipos de traducción. Incluso creo que Jodorowsky inventó un tipo de traducción muy particular que enseña en su dormitorio. [...] Superior a la de Nicanor Parra. [...] Borges creía que la traducción podía superar al original y que la alternativa y potencialmente contradictoria revisión del original podía ser igualmente válida, más aún, que el original o la traducción literal no tenía porqué ser fiel a la traducción. Gombrowicz se traducía a sí mismo y se plagiaba a sí mismo (Apablaza 2010a, pp. 69-70).

Jodorowsky, Nicanor Parra y Gombrowicz, junto a Borges, quien parece dar la clave de todo este proceso, ya que la cita es una forma del pasaje entre textos, lo que es una forma de traducir un texto en otro: aunque se copie literalmente un texto, igualmente se transpondrá, será otro; bien lo sabemos por Pierre Menard. De igual manera, la cita/ copia/traducción libre, errónea o directamente apócrifa se asume como válida, porque la fidelidad no necesariamente es una variable que entra en juego para definir lo literario.

El siglo XXI, que ha comenzado con un fuerte protagonismo de la noción de archivo (una fuerte noción de pasado), ofrece procesos escriturales y de lectura para la reedición, remezcla, copia, (re)colección documental, que "transforma a los propios escritores de literatura, más que en escritores, en operadores de archivos" (Mendoza 2019). Apablaza opera sobre los archivos de las tradiciones literarias argentina y chilena, los parafrasea, los transpone, los reescribe, interpelándolo a través del gesto de la imposibilidad y la ilegibilidad, pero también explicitando la impronta evidentemente machista que signó su configuración.

En Apablaza, el canon chileno se reconfigura a través de un Bolaño que escribe un libro imposible y xenófobo, otro Bolaño que fingió su muerte y está en realidad en la Antártida o en Arizona (Apablaza 2010b: 36-37), el fantasma de Manuel Rojas que habita el Centro Cultural homónimo (Apablaza 2010b: 61-62), y la vida de Gabriela Mistral reformulada en EME/A. La tristeza de la no historia (Apablaza 2010b: 55-58). A su vez, Mariana Callejas, agente de la DINA, es invocada por un escritor en "Consejos para una 
joven cuentista", para recuperar su lugar en la tradición ante unos jóvenes cuentistas que no saben nada de ella y tienen que buscarla en Google (Apablaza 2011a: 51).

\section{Algunos cambios}

En 2011, Apablaza edita Junta de vecinas. Antología de narradoras chilenas contemporáneas, donde seleccionó trabajos de Alejandra Costamagna, Nona Fernández, Andrea Jeftanovic, Leo Marcazzolo, Andrea Maturana, Carolina Melys, Lina Meruane, María José Navia, Patricia Poblete Alday, Eugenia Prado Bassi, Cynthia Rimsky, Mónica Ríos, María Paz Rodríguez, Francisca Solar, María José Viera-Gallo y Lyuba Yez. A su vez, Apablaza escribió el prólogo de la antología, titulado "Infancia y desarraigo".

En ese prólogo, Apablaza se pregunta qué es lo que hay en esa "tendencia constante al olvido" que se observa en las editoriales chilenas ante un proyecto de antología de escritoras contemporáneas como el que ella ha llevado a cabo. Para Apablaza, Junta de vecinas "ha sido dejada de lado debido a que toda selección de autores para cualquier antología suele ser ingrata, ya que no siempre concuerda con el gusto de autores, críticos y lectores en general" (Apablaza 2011b: 10). La idea del cupo que habíamos mencionado cuando reflexionamos sobre el cuento de Nasón resuena: hacia el 2011 el panorama editorial es lo suficientemente reducido como para que una antología de escritoras pueda suscitar tensiones en el horizonte de la crítica, de los/as autores/as y de la audiencia.

51 En el prólogo, Apablaza también sostiene que, "lejos de una imagen representativa o de un eje común que guíe las producciones de las escritoras seleccionadas", nos "encontraremos con una combinación heterogénea que supongo burla la homogeneidad propuesta por los proyectos de un sujeto masculino que da uniformidad a lo disperso, a lo plural". Antes como escritora y ahora como editora, observamos en Apablaza la idea de un tipo de escritura que evidencia al mismo tiempo que se distancia de un canon narrativo masculino. Las autoras seleccionadas y prologadas por Apablaza "no responde[n] necesariamente a la subordinación en el marco de las estructuras de poder y el oficialismo" (Apablaza 2011b: 13).

En la antología se "encuentra la búsqueda de un lenguaje que inaugure, un lenguaje con el que se experimenta para construir un mundo, de allí su cercanía a la poesía y la tradición poética que supone la literatura chilena como conjunto". De nuevo, se observa la idea del experimento y del juego, además del género poético como un tratamiento diferente del lenguaje: $G O \emptyset$ dice que "A veces me siento como Sylvia, como Alejandra Pizarnik" (Apablaza 2012: 97). Los textos narrativos (de las escritoras, de Apablaza) emprenden la búsqueda (discontinua, a menudo irresoluta, pero que no teme al fracaso) de un lenguaje "que se va construyendo" en los propios textos. Apablaza sostiene que ese lenguaje que se busca inaugura una nueva forma de decir que "lejos de respetar formas inmutables cada nuevo texto tiende a construir sus leyes de funcionamiento al mismo tiempo que a producir su destrucción (Apablaza 2011b: 14-15).

53 La conferencia "Escribir en dictadura, escribir en postdictadura: silencio, censura, resistencia y rebeldía en la literatura chilena", que Apablaza impartió en 2018, identifica ciertos cambios que se han suscitado en el sistema literario chileno a partir del año 2010: 

diferencia de lo que sucedía hace 10 años atrás, donde el campo era un campo liderado por hombres o propuestas masculinizadas en pro de la pertenencia a un cierto grupo (Apablaza 2019: 173). como determinante de ciertos lineamientos poéticos, que se conformarán en los criterios que permiten formar parte de "cierto grupo", de cierta biblioteca.

56 Constanza Gutiérrez Carmen Galdames, María José Navia, entre otras "han sido publicados en nuevo panorama editorial postdictadura, donde se presencia altas posibilidades de publicación de libros por la apertura y ampliación del campo editorial". Apablaza destaca la aparición de "editoriales independientes o microeditoriales", lo que facilita que haya "una gran diversidad de propuestas de escritura, estéticas, formas de narrar que llenan un vacío que se vivió en generaciones anteriores" (Apablaza 2019: 174). La misma Apablaza ha sido parte de ese cambio, ya que en 2015 funda la editorial Libros de la Mujer Rota.

\section{Reflexiones finales}

Macarena Areco, junto con su equipo conformado por Marcial Huneeus, Jorge Manzi y Catalina Olea, propone dividir el mapa de la novelística chilena de las últimas décadas en cuatro territorios genéricos: "los realismos, los experimentalismos, los subgéneros y las hibridaciones" (Areco 2018: 60). Areco caracteriza a las narrativas híbridas por la "mezcla de subgéneros discursivos y narrativos, especialmente masivos" (policial, novela histórica, testimonio); la multiplicidad y la fragmentación de la estructura, el tiempo, el espacio, las voces y las tramas; la "desterritorialización", que puede ser entendida como diseminación geográfica o como el cuestionamiento de los límites entre literatura y ficción, seres y objetos, géneros narrativos; y la "transtextualidad" (Areco 2015: 77). En relación con este último rasgo, "son fundamentales la metaliteratura y la relevante presencia de citas pertenecientes a la cultura popular mezcladas con referencias canónicas, además de la aparición de formas no discursivas, como los esquemas gráficos, la fotografía y el cine" (Areco 2018: 63).

Lorena Amaro, por su parte, propone que, en los últimos años, "ha hecho su irrupción una nueva forma narrativa, vinculada desde sus orígenes [...] al género autobiográfico: la autoficción". En las más recientes "autoficciones", los recursos y las técnicas narrativas contemporáneas van "oscureciendo la "verdad" del referente". Entre quienes trabajan con la autoficción Amaro identifica a Germán Marín, Lina Meruane, Cynthia Rimsky, Nona Fernández, Rafael Gumucio, Alejandro Zambra, Leonardo Sanhueza, Luis López-Aliaga y Claudia Apablaza (Amaro 2015: 37-39). La autoficción es "una forma de reflexión escritural que pone en suspenso lo autobiográfico, difiriéndolo, desplazándolo hacia la novela, pero sin llegar a ella: sin ser novela autobiográfica" (Amaro 2018: 21).

El análisis de Amaro puede articularse con el de los territorios genéricos de Areco, ya que la autoficción puede desplegarse en el marco de narrativas híbridas. Olea explica que, en la actualidad, es dificultoso sostener un "realismo a secas", con lo que a menudo

Cuadernos LIRICO, 23 | 2021 
se emplean procedimientos antimiméticos, autoficcionales y metatextuales (Areco 2018).

Los trabajos de Amaro y de Areco nos permiten entender que la producción de Apablaza puede enmarcarse en un territorio más amplio, o mejor dicho, que las características que hemos analizado encuentran vinculación con algunos lineamientos poéticos de ciertas narrativas chilenas de los últimos años. Más que rastrear dónde está lo autoficcional, lo metaliterario, las referencias a la cultura popular o la estética de los medios digitales en Apablaza, lo que nos interesa destacar de Areco y Amaro es la idea de la hibridez, de distanciarse de ciertos cánones, pero sin querer constituir otros nuevos. No es que en los textos de Apablaza se borran las tradiciones literarias argentinas y chilenas, sino que se las vuelve a escribir evidenciando su carácter masculino. La utilización de imágenes que subrayan la imposibilidad de pertenecer al libro o a la biblioteca indican que efectivamente hay limitaciones en lo que respecta al género de quién produce el texto y a las modalidades narrativas que se consideran canónicas.

61 En los textos de Apablaza, se va hacia y se reescriben la tradición argentina y la tradición chilena, a través de la experimentación. La biblioteca es deseada; sin embargo, también se la presenta como ilegible, absurda, imposible, expulsiva. La solución es experimentar con las citas, las formas del relato, las figuras, los roles. El experimento vuelve fragmentario lo unificado, distante lo cercano, agitado lo calmo. Apablaza asume como propias diversas tradiciones y las reescribe, como ensayo, como juego.

62 Giorgio Agamben sostiene que el juego modifica y destruye el tiempo. A partir de las maneras con que ciertos ritos fijan las etapas de los calendarios, Agamben conjetura una relación "al mismo tiempo de correspondencia y de oposición entre el juego y el rito": el rito fija y estructura el calendario, el tiempo; mientras que el juego los altera y los destruye (Agamben 2007: 95-106). Si el rito ha canonizado y estructurado de cierta manera las literaturas chilena y argentina modernas y contemporáneas, en Apablaza el juego exhibe, para distanciarse, los mecanismos con que se han conformado esas tradiciones, las formas narrativas, determinada figura del escritor latinoamericano. Es un ida y vuelta de correspondencia y oposición, de ensayo y error: se alude permanentemente al "canon narrativo ideal" y masculino, pero se separa de él; las voces narradoras declaran no estar construyendo relatos, pero en realidad sí lo hacen; hay una miríada de citas de la cultura letrada, pero está enmarcada en textos digitales considerados "no literarios"; los tuits y las entradas de los blogs parecen novedosos, pero remedan géneros discursivos del siglo XIX; se desea entrar a la biblioteca, pero ello resulta intrínsecamente imposible.

\section{BIBLIOGRAFÍA}

Agamben, Giorgio, "El país de los juguetes. Reflexiones sobre la historia y el juego", Infancia e historia. Destrucción de la experiencia y origen de la historia, Buenos Aires: Adriana Hidalgo, p. 94-108 
Amaro, Lorena, “La pose autobiográfica”, Revista Dossier, № 30, 2015, p. 37-41.

---, La pose autobiográfica. Ensayos sobre la narrativa chilena, Santiago de Chile, Ediciones Universidad Alberto Hurtado, 2018.

Apablaza, Claudia, Autoformato, Santiago de Chile, LOM Ediciones, 2006.

---, Diario de las especies, Barcelona, Ediciones Barataria, 2010a.

---, EME/A. La tristeza de la no historia, Santiago de Chile, Editorial Cuarto Propio, 2010b.

---, “Anti-cuentos, fracaso narrativo, belleza y felicidad", Letras.S.5, 2010c, https://

web.archive.org/web/20160817011612/http://letras.s5.com/ca251110.html

---, Siempre te creíste la Virginia Woolf, Santiago de Chile, La Calabaza del Diablo, 2011a.

---, "Prólogo: infancia y desarraigo", Claudia Apablaza (ed.), Junta de vecinas. Antología de narradoras chilenas contemporáneas, Madrid, Algaida, 2011b, p. 7-17.

---, GOø y el amor, La Habana, Editorial Arte y Literatura, 2012.

---, Todos piensan que soy un faquir, Santiago de Chile, Edicola, 2013.

---, Diario de quedar embarazada, Santiago de Chile, Penguin Random House, 2017.

---, "Escribir en dictadura, escribir en postdictadura: silencio, censura, resistencia y rebeldía en la literatura chilena", Revista Herencia, Vol. 32, 1, enero-junio, 2019, p. 163-176.

Areco, Macarena, Cartografía de la novela chilena reciente, realismos, experimentalismos, hibridaciones y subgéneros, Santiago de Chile, Ceibo, 2015.

---, Cartografía e imaginarios de la narrativa latinoamericana reciente: Argentina, Chile y México, Monográficos SINOELE. IX Congreso Internacional de la Asociación Asiática de Hispanistas, Bangkok 2016, № 17,2018 , p. 59-69

Bianchi, Soledad, Pliegues. Chile: cultura y memoria (1990-2013), Santiago de Chile, Editorial Cuneta, 2014.

Bolter, Jay David, \& Grusin, Richard, Remediation. Understanding New Media, Cambridge, Massachusetts: MIT Press, 2000.

Chejfec, Sergio, Últimas noticias sobre la escritura, Buenos Aires, Entropía, 2015.

Foucault, Michel, “Lenguaje y literatura”, De lenguaje y literatura, Barcelona, Paidós, 1996, p. 63-103.

Goldsmith, Kenneth, Escritura no-creativa. Gestionando el lenguaje en la era digital, Buenos Aires, Caja Negra Editora, 2015.

Guerrero, Gustavo, Paisajes en movimiento. Literatura y cambio cultural entre dos siglos, Buenos Aires, Eterna Cadencia, 2018.

León, Gonzalo, “La risa de Apablaza”, Letras.S.5, 2011, http://letras.mysite.com/ca191111.html

Mendoza, Juan José, “El Remodernismo. Literatura argentina y después... [Un ensayo]”, El matadero, $\mathrm{n}^{\mathrm{o}}$ 10, 2016, p. 69-82.

---, Los archivos. Papeles para la nación, Villa María, Eduvim, 2019.

Perloff, Marjorie, Unoriginal Genius: Poetry by Other Means in the New Century, Chicago, The University of Chicago Press, 2010.

Piglia, Ricardo, Crítica y ficción, Buenos Aires, Seix Barral, 2000. 
Rivera Garza, Cristina, Los muertos indóciles. Necroescrituras y desapropiación, México DF, Tusquets, 2013.

Schmitter, Gianna, “Entrevista a Claudia Apablaza”, LL Journal, Vol. 11, no 1, 2016, Nueva York, City University of New York, p. 1-21.

\section{RESÚMENES}

El artículo examina cómo en los textos de Claudia Apablaza se leen y se (re)escriben a los sistemas literarios argentino y chileno. En los textos de Apablaza, se establece una relación temporal con el pasado que no está basada en una mera repetición, sino en un proceso que subraya las tensiones y la fragmentación, a partir de la cita y del empleo de ciertas figuras y formas narrativas. En la escritura ficcional de Apablaza encontramos libros y bibliotecas imposibles e inexistentes, así como narraciones fragmentarias, para reflexionar sobre determinadas zonas puntuales y dinámicas de las literaturas chilena y argentina durante el siglo XX y el siglo XXI.

Nous examinons les textes de Claudia Apablaza, où les systèmes littéraires argentin et chilien sont lus et (ré) écrits. Dans les textes d'Apablaza s'établit une liaison temporelle avec le passé qui ne se réduit pas à une simple répétition. Il s'agit d'un processus qui souligne les tensions et la fragmentation, fondé sur la citation et l'utilisation de certaines figures et formes narratives. Dans les récits d'Apablaza on trouve aussi bien des livres et des bibliothèques impossibles et inexistants que des récits fragmentaires, qui nous permettent de réfléchir sur certains domaines spécifiques et dynamiques de la littérature chilienne et argentine des XXe et XXIe siècles.

This paper examines how in Claudia Apablaza's texts the Argentine and the Chilean literary systems are read and (re)written. In Apablaza's texts, a temporary relationship with the past is established that is not based on mere repetition, but on a process that underlines tensions and fragmentation, based on citation and the use of certain figures and narrative forms. In Apablaza's fiction, we find impossible and non-existent books and libraries, as well as fragmentary narratives, that makes us reflect on certain specific and dynamic areas of chilean and Argentine literature during the 20th and 21st centuries.

\section{ÍNDICE}

Palabras claves: tradición, citación, reescritura, canon, biblioteca

Mots-clés: tradition, citation, réécriture, canon, bibliothèque

Keywords: tradition, quotation, rewriting, canon, library

\section{AUTOR}

\section{ANDRÉS OLAIZOLA}

Instituto de Investigaciones Bibliográficas y Crítica Textual (CONICET)

aolaizola@gmail.com 